\title{
Zero Waste Technologies and Solution of Economic and Environmental Problems of Sustainable Development
}

\author{
Elena Dotsenko ${ }^{1, *}$, Natalia Ezdina ${ }^{1}$, and Svetlana Mudrova ${ }^{1}$ \\ ${ }^{1}$ Russian University of Economics, Department of Political Economy and History of Economic \\ Science, 117997 Moscow, 36 Stremyanny lane, Russia
}

\begin{abstract}
Economic and environmental problems are closely related, and solving some of them, the others cannot be solved. The state of the environment directly forms the potential of the economic sphere. For example, resources for industrial enterprises are formed in the natural environment, and the capacity of plants and factories depends on resources' quantity. The amount of money to be spent on the purchase and installation of treatment plants, on the measures to eliminate water, air and soil pollution, depends upon the profit. Each country has its own list of environmental problems related to the economy. They are engaged in their elimination at the state level, but first of all the responsibility for the consequences is the burden of companies' management. The active development of the economy should not adversely affect the state of the environment. Both individual enterprises and whole states should control the economic and environmental situation in order to achieve a balance and solve global problems. The most important form of interaction between the state and business in solving economic-and-environmental problems is the introduction of zero waste technologies in all their diversity and achieving their multiplicative effect. The paper shows the relationship between environmentally-oriented innovative development of the economy and the introduction of zero waste technologies.
\end{abstract}

\section{Introduction}

The environmental problems caused by rapid economic development around the world are numerous: the depletion of natural resources, especially non-renewable; large amounts of industrial wastes; environmental pollution with radioactive and toxic elements; lowering the fertility of the land; reduction of agricultural land; lower production efficiency; the use of outdated and unsafe equipment; deterioration of working conditions of people; lack of rationalization of land and water resources management [1. Human activities have a negative impact on the environmental conditions. Many experts rely on the large-scale introduction of zero waste technologies that will help solve the problem of air, hydrosphere, lithosphere pollution, reduce the amount of garbage [2-3].

\footnotetext{
* Corresponding author: ktyf110372@,rambler.ru
} 
The potential positive environmental effect of zero waste technology is immense. It is estimated that up to 20 tons per capita of various raw materials are processed annually in Russian Federation, with only 5-10\% going to finished products [4]. Everything else is waste, the unused portion of raw materials. During the consuming of industrial products, as they wear out or become obsolete, they also go into the category of consumer waste. Thus, almost the entire volume of materials taken from nature is returned to it, but already with new properties - as the waste, that lead to a violation of the ecological balance.

\section{Materials and Methods}

The analysis of domestic and foreign publications shows that zero waste technologies can be developed in four main areas [5-8]:

1) Creation of various types of drainless technological systems based on existing, implemented and promising water cleaning methods. In this case, a sharp decrease in water consumption is achieved, but, as a rule, secondary pollution in the form of solid precipitates or saturated solutions is formed.

2) Development and implementation of systems for the processing of production and consumption wastes, which should be considered not as an environmental burden, but as a source of additional income. It should be considered that during the operation of modern water and gas cleaning systems, solid waste is formed, which is a complex and concentrated mixture of pollutants.

3) Organization of fundamentally new processes for the production of traditional types of goods, which make it possible to eliminate or reduce the processing stages or technological stages at which the main amount of waste is generated.

4) Development and creation of territorial-and-industrial complexes (TIC) with a closed structure of flows of raw materials and waste within TIC with a minimum of emissions.

The tasks for zero waste technologies implementation arise from the following provisions:

- most of the environmental pollution is the result of insufficient development of industrial technologies;

- the unused production waste is the loss of natural resources;

- the production and use of secondary raw materials (waste) with an increase in the demand

- for natural materials can be an important source of increasing the labor productivity;

- the prerequisite for the rationalization of industrial technologies is the development of technical and economic solutions for "closed" technologies (the circulation of materials);

- the universal and resource-saving way to solve the basic problems in the field of metabolism between man and nature should be carried out on a state scale.

The emission of toxic components from waste gases and wastewater was carried out mainly for the conversion of these components in a harmless form and rarely combined with their reuse [9]. In many cases, the enterprises attempted to reduce the concentration of toxic wastes during their removal into the biosphere [10]. The measures to reduce industrial waste and wasting heat in the production of goods, as well as the recycling of these wastes were implemented primarily in order to save materials and energy and were not considered as measures to protect the environment.

The constant rise in the use of natural resources, increased pollution of the environment require the implementation of a zero waste technology strategy. The basis of this technology means the fact that unused production waste is at the same time not fully utilized natural resources and a source of environmental pollution. Reducing the amount of waste used in relation to the amount of manufactured products will allow to produce more products from the same amount of raw materials and will be an effective measure of environmental protection. 
The biosphere provides the natural resources from which the goods are manufactured in the production area, and the waste is generated. In many cases, after appropriate treatment, they can be used as secondary raw materials or as secondary energy sources [11]. If it is impossible or economically unprofitable for technical or technological reasons, they should be brought into the biosphere in such a way as not to harm the natural environment.

\section{Results and Discussion}

Because of its activities, humanity has come to understand that it is necessary to introduce technological processes that produce minimal emissions, in which the self-cleaning ability of nature sufficiently will prevent the occurrence of irreversible environmental changes. Specialists have proposed the definition of zero waste technology, which is taken as the main one for further use [12-14]:

Zero waste technology is the practical application of knowledge, methods and means to ensure the rational use of natural resources, energy and environmental protection within human needs.

By zero waste technology is meant an ideal production model, which in most cases cannot be fully realized, but with the development of technical progress, it is increasingly approaching the ideal one. More specifically, zero waste technological system should be understood as such production, as a result of which activity there are no emissions to the environment. Zero waste production is a set of organizational and technical measures, technological processes, equipment, materials, ensuring maximum and integrated use of raw materials and minimizing the negative impact of waste on the environment.

Zero waste production can be characterized by all possible disposal of waste generated in direct technological processes. Low-waste technology is an intermediate stage of zero waste and differs from it when provides the finished product with not fully recyclable waste.

The final achievement of zero waste production is due to the presence of $n$ number of stages for processing waste of all types. The system becomes zero waste when at the nth stage such an amount of waste is released that does not have a noticeable negative impact on the environment. If the waste at some stages is sent back for recycling, the zero waste technology of a closed or partially closed type is obtained at the initial stage of production.

The main recommendations on the elements of zero waste technologies can be presented as follows:

- for raw materials, half-finished products, energy, refrigeration facilities: maximize waste and waste heat reuse; minimalize use of raw materials, semi-finished products and working energy in the extraction and manufacture of which relatively large quantities of industrial waste and waste heat are produced, or which are only available in limited quantities (for example, electricity or cooling water); as far as possible, avoid the use of raw materials containing a high proportion of useless impurities;

- for industrial equipment: use technical devices with a long service life and low weight, made in accordance with the requirements of zero waste technology; use the devices of the optimal principle of action, for example, with a high degree of separation or with a high rate of heat and mass transfer, with minimal pressure loss and low heat loss;

- for the main processes: use the processes consuming the energy not intensively, with high selectivity; apply highly efficient catalytic processes;

- for technological schemes: apply the principle of counterflow or circulation; avoid the principle of forward flow and mixing;

- for process parameters: select the optimal reaction temperature; choose small driving forces; exclude extreme technological parameters, for example, temperature and pressure;

- for the goods produced: put in the design (composition) of the product a small specific mass, provide for a long service life, as well as minimal waste and waste heat during its use; ensure 
the suitability of the worn out (spent) product as a secondary raw material (secondary energy source);

- for waste, waste heat: receive waste in recyclable form.

Since these requirements are partly contradictory, and partly not feasible due to the lack of opportunities, then for each process it is necessary to look for the optimum taking into account labor productivity and economy.

One of the promising, profitable and developing areas for the use of waste included in the system of zero waste technologies is the exchange of them both between enterprises within countries and between states in order to use them in suitable technological processes.

Thus, export and import of polymer wastes are widely developed in the countries of the EU, as well as in Austria, Switzerland and the Scandinavian countries [15]. Polymers, polyethylene, polypropylene, polystyrene, polyvinyl chloride and cellulose acetate are in special demand. The leading position in the European exchange of waste is occupied by Italy (annual imports amount to over 90 thousand tons of polymer waste), Germany (export 65 thousand tons) and France (export 50 thousand tons). Japan, China and other countries satisfy most of the metal requirement by importing scrap metal from other countries. China imports garbage from the United States to produce the paper [16].

Currently in Western Europe and the USA there are two types of intermediary exchanges: exchanges that supply information on the amount of waste, their qualitative composition and processing methods, and exchanges that directly exchange waste by finding the appropriate consumer.

The successful functioning of such systems, completing the cycle of zero waste technologies in their own way, is possible on the basis of automated means of communication and control, which carry out their operations on an interstate scale or within an industrial area [17-18]. Thus, since the mid-1970s, waste of wood, paper, cardboard, metals and other industrial wastes has been implemented in Germany and France through the mediation of exchanges between enterprises. Despite relatively small contacts between the supplier and the consumer, such exchanges are economically beneficial for the state [19-20]. The experience of the United States and Japan, which has a wide network of intermediary exchanges that promote the introduction of advanced technological processes of neutralization and recycling of industrial waste and the exchange of waste between enterprises, shows the same picture.

For the rational management of an integrated system for collecting, transporting, neutralizing and disposing of waste and pollution throughout a whole industrial region, a single country or a group of countries, it is necessary to have up-to-date information on the location of waste, its quantity, composition and properties, possibilities of disposal or disposal. Information retrieval systems make it possible to define and establish relations "waste to raw materials", "supplier to consumer". Coordination centers for the mutual exchange of industrial waste for the purpose of their further disposal, for example, operate successfully in Japan.

At present, locational connections and combinations of various technological processes with municipal consumption areas are becoming increasingly important for the use of waste and waste heat. Therefore, in many cases it is possible to use water first for household purposes, and then after cleaning, requiring relatively small costs, to use for production purposes.

The non-drainage system of industrial water use is a special type of zero waste technology, in which at least $90 \%$ stays within the water circulation cycle and not more than $10 \%$ is supplied by fresh water. At the same time, it is necessary that the amount of disposed water discharged from the system into the reservoir or into the treatment plant does not exceed $5 \%$ of the whole water circulation volume. 
Non-drainage systems, in turn, are subdivided into systems with full utilization of components or without utilization, i.e. with storage in special tanks, drives or with injection into underground horizons.

From a technological point of view, to introduce zero waste and low-waste production, there is an imperative to create new materials and substances, for example, new membrane materials, ion exchange resins, synthetic flocculants, chemical reagents, as well as devices that will improve or intensify various media separation, neutralization and waste management processes. To expand the scale of introduction of zero waste technological processes, further improvement of waste utilization methods as well as new economic incentives is needed in order to increase the interest of managers from various industries in the preparation of waste for subsequent recycling and disposal. An important incentive is also the reduction of the consumption of natural raw materials planned by the enterprise, and the transition to the use of secondary material resources.

For the organization of zero waste and low-waste industrial production, cooperation of enterprises of various industries is of exceptional importance. The most favorable opportunities for co-production are formed in the conditions of the territorial-and-production complex, where a set of interrelated and interdependent, proportionally developing facilities of various sectors of the national economy is planned. These objects are created for the joint solution of one or several specific economic problems. They are distinguished by the size of production and a clear specialization throughout the country and its economic regions. They are concentrated on a limited, necessarily compact territory, which has the necessary set and quantity of resources sufficient to solve the corresponding tasks of zero waste production development.

In addition, the territorial-and-production complex effectively use local and external resources (from the national economy point of view), provide environmental protection, and has a unified production and environmental-saving infrastructure.

Economic advantages with proper and optimal development of industrial territorial-andproduction complex allow advantageous and expedient transportation of waste over relatively short distances within TIC, which facilitates the solution of many issues related to the territorial distribution of enterprises.

\section{Conclusion}

Based on all the above, we can conclude that the further development of the economy in the environmental aspect is closely connected with solving the problems of a more complete use of natural resources and with the creation of recycling material and energy flows. The economic evaluation of the effectiveness of zero waste technologies consists in determining the economic effect of recycling at all stages, including other industries, as well as calculating the prevented damage to the environment based on a comparison of the companies using zero waste technologies and the enterprises with traditional technologies. The creation of lowwaste and zero waste territorial-and-industrial complexes is an important direction in the development of the national economy, the rational use of natural resources and the preservation of ecological balance.

\section{References}

1. T. Gvozdkova, M. Tyulenev, S. Zhironkin, V. A. Trifonov, Yu. M. Osipov, IOP Conf. Ser.: Earth Environ. Sci., 50:1, 012010 (2017)

2. M. Tyulenev, S. Markov, M. Cehlar, S. Zhironkin, M. Gasanov, Acta Montanistica Slovaca, 23:4, 368-377 (2018) 
3. M.A. Tyulenev, S.O. Markov, M.A. Gasanov, S.A. Zhironkin, Geotech. Geol. Eng., 36:5, 2789-2797 (2018)

4. A.G. Koryakov, M.V. Kulikov, Economics and Innovation Management, 4, 16-26 (2018) DOI: $10.26730 / 2587-5574-2018-4-16-26$

5. M. Cehlár, R. Rybár, J. Pinka, L. Haxhiu, M. Beer, Arch. Min. Sc., 58:2, 557-568 (2013)

6. R. Rybár, M. Beer, M. Cehlár, Measurement, 88, 153-164 (2016)

7. M. Cehlár, J. Janočko, Z. Šimková, T. Pavlik, M. Tyulenev, S. Zhironkin, M. Gasanov, Resources, 8:1, 21 (2019)

8. S. Zhironkin, D. Khloptsov, N. Skrylnikova, I. Petinenko, O. Zhironkina, E3S Web Conf., 41, 04010 (2018)

9. M. Tyulenev, S. Zhironkin, O. Litvin, Pollution Research, 34, 825 (2015)

10. M. Tyulenev, S. Zhironkin, K. Kolotov, E. Garina, Poll. Res., 35, 221 (2016)

11. V. Kovalev, B. Gerike, A. Khoreshok, P. Gerike, Taishan Academic Forum-Project on Mine Disaster Prevention and Control, 184 (2014)

12. N. Gilyazidinova, N. Rudkovskaya, T. Santalova, E3S Web Conf., 41, 02017 (2018)

13. A. Gianoncelli, A. Zacco, R. Struis, L. Borgese, L. E. Depero, E. Bontempi, Env. Chem. Sust. World, 4, 103 (2013)

14. O. Kononchuk, A. Alekseev, O. Zubkova, V. Udovitsky, E3S Web Conf., 21, 02003 (2017)

15. I. Kotarska1, B. Mizera, P. Stefanek, E3S Web Conf., 41, 02013 (2018)

16. M. Samir, F. Alama, P. Buysse, T. Nylen, O. Ostanin, E3S Web Conf., 41, 02012 (2018)

17. A. Kovalev, N. Rebrova, M. Zhidkova, E3S Web of Conf., 41, 04026 (2018)

18. V. Frolova, O. Dolina, T. Shpilkina, E3S Web of Conf., 41, 04027 (2018)

19. O. Borisova, V. Frolova, M. Livson, V. Biryukov, E3S Web of Conf., 41, 04028 (2018)

20. V. Prusova, V. Beznovskay, I. Politkovskaya, E3S Web of Conf., 41, 02008 (2018) 